\title{
Effect of Omega's different sources supplementation on some biological assessments and mental efficiency at adolescence
}

\author{
Sohila A.F. Hassan ${ }^{1}$, El Sayed A.E. Zidan ${ }^{1}$, El Sayed A.K.Hassanin ${ }^{2}$ \\ Walaa I. Mohamed ${ }^{1}$ and Reda A. Mohammed ${ }^{1}$ \\ 1- Faculty of Specific Education, Ain Shams University \\ 2- $\quad$ National Nitration Institute, Ministry of Health, Cairo, Egypt
}

\begin{abstract}
Food plays an important role in influencing the students' learning behavior and achievement through a few basics. This study aimed to improve nutritional status (especially hemoglobin and lipid profile) and developing the mental efficiency (especially perception , remembering and attention ) in adolescence using various rich sources of omegas (3,6 and 9). Also, to compare the effectiveness of natural food sources with the medical supplements of them. Forty eight adolescents (12-15 yrs) with institutionalized nutrition were subjected and divided to 3 groups (each of $16 ; 8 \mathrm{M} \& 8 \mathrm{~F}$ ). The first group was served as control, while the second and the third ones were enriched and supplemented equally with natural and medical sources of omegas for three consequence months. Nutritional assessment was also surveyed for the subjects ( $24 \mathrm{hrs}$. recall for three continuous days). Biological analysis for Hb. , AST, ALT , TG , TC , HDL-C , LDL-C and VLDL-C had been taken place pre and post supplying intervention. Psychological test was applied also pre and post supplying intervention to assess the perception, attention and remember for them.

Results showed that both kinds of intervention increased significantly ( $\mathrm{p} \leq 0.01) \mathrm{Hb}$ and HDL-C , while decreased significantly $(\mathrm{p} \leq 0.01)$ ALT , AST , TG , TC , LDL-C . VLDL-C in serum of the studied adolescents. On the other hand, psychological test revealed significant development statistically $(\mathrm{p} \leq 0.01)$ after three months of interventions comparing with the control group or even with the pre test assessment.

In conclusion : supplementation with natural or medical omegas for adolescence could improve the mental efficiency ( especially perception, attention, remember ) after three months without discrimination for the source used.
\end{abstract}

key words : Omega, nutrition, supplementation, mental efficiency, perception, attention, remember, adolescence .

\section{INTRODUCTION}

Long-chain polyunsaturated fatty acids (PUFAs) fall into two main families: omega-3 and omega-6. Omega-3 PUFAs are derived from fish and some plants, whereas omega-6 PUFAs are derived mainly from vegetable oil. Omega 3 fatty acids is a group of unsaturated fatty acids and is important for many functions in the human body. These acids are found in foods, fatty fish and oysters, and some are found in vegetable oils and are also available in the form of dietary supplements (Covington, 2004).
The principal precursors of omega3 and omega-6 PUFAs can not be endogenously synthesized from carbohydrates (Mazza et al., 2007). Thus, the source of $\alpha$-Linolenic acid (ALA) with 18 carbons, 3 double bonds, the first located at the third carbon from the last ( $\omega)$ (18:3: $\omega 3)$, and Linoleic acid (LA$18: 2 \omega 6)$, are entirely nutritional. ALA is converted in the body to Eicosapentaenoic acid (EPA-20:5: 133$)$ and Docosahexaenoic acid (DHA-22:6: $\omega 3$ ) comprising the omega-3 group. Similarly, LA is converted to Arachidonic acid (AA20:4: $\omega 6$ ), representing the omega-6 group. 
Sohila A.F. Hassan et al.

The conversion of the precursors to omega $3 / 6$ acids is performed by an enzymatic system of elongation and desaturation which is responsible for the steady state ratio of $\omega 3 / \omega 6$, vital for normal membrane fluidity. The specific concentrations of omega-3 and omega-6 PUFAs in blood or cell membranes reflect dietary intakes (Gadoth, 2008).

Fat is $15-30 \%$ of the dry weight of the brain and is essential for the growth of brain function. It was noted that the low level of fatty acids, especially omega- 3 in the blood is linked to a range of behavioral disorders, including attention deficit and hyperactivity. The physical and behavioral symptoms of the lack of essential fatty acids are similar to those of attention deficit disorder and hyperactivity. Therefore, it is conceivable that omega-3 deficiency or dysfunctions of fatty acids may contribute to symptoms in patients with attention deficit disorder and hyperactivity (Antalis et al., 2006; Mcnamara and Carlson, 2006; Germano et al., 2007; Sorgiet al., 2007).

Omega-3 and Omega-6 fatty acids are important components of cell membranes and act on cell wall permeability. Omega-3 fatty acids also act on the prevention of heart disease and have anti-inflammatory effects that may be important in other diseases. There is increasing interest in the role of omega fatty acids 3 in the prevention of diabetes and certain types of cancer (Lunn et al., 2006)

There are many cognitive processes in human, first of them is attention, it is one of the most important cognitive processes in cognitive psychology. The attention process is the main input to all cognitive processes that take place within the system, such as reading comprehension, linguistic comprehension, auditory and visual perception, memory and learning. The second one is perception, it is the process by which we organize, interpret and make sense of the patterns of stimuli. The term cognition in psychology is used to refer to the direct knowledge of the world and to our bodies because of neurological signals from the sensory organs of the eye, ear, nose, tongue and skin. The last one is remembering, the process of remembering is a series of efforts aimed at the whole range of treatments carried out by the person remembered from the moment to the end of the task of perception. This means preparing a subject for gradual introduction into long-term memory, and retaining it for its next retrieval ( محمد ناجي (سعد 2007)

Adolescence is the second important stage after the infant phase due to the similar rapid growth in each. Therefore, special nutrition recommendations are required in all nutrients to meet the needs and requirements for growth. Early adolescence begins with rapid growth in both sexes and begins in females early than age 9. - 11 years and up to 14 years, either in males from 11 to 13 years and up to 16 years (يفيلين سعيد 2005)

Adolescence is characterized by the growth of all mental functions, where the adolescent reaches about $95 \%$ of his intelligence and mental abilities are directed towards accuracy as the speed of achievement and grow memory. Mental growth requirements at this stage include: Considering individual differences in capacity. Attention to mental abilities and innovation in adolescents. Exploiting the level of ambition among adolescents. The diversity of courses and methods to agree with the differences of the adolescents in the capacity (حامد عبد السلام زهران 2005).

The aim of this research is to study the effect of supplementation with different sources of omega on the nutritional status and mental efficiency in adolescence. Through the following subgoals:

1. Improve nutritional status, especially hemoglobin and lipid profile in adolescence using various sources rich in omega. 

and mental efficiency at adolescence

2. Developing the mental efficiency, especially perception, remembering and attention in adolescence, using various sources rich in omega.

3 - Comparing the effectiveness of natural or medical sources of omegas on the nutritional status or mental efficiency.

\section{MATERIALS AND METHODES}

The study included 48 adolescence (24male) from " Dar elamel", " Hadayek Al-Kobba " and ( 24 female) from " el shraiaa ", " EL Matria " , Cairo , Egypt their age ranged from $12-15$ years .Demographic data, Dietary assessment had been complied. The subjects were divided into three groups randomly.

Group 1 controls $(n=16)$ : Consists of 8 males and 8 females.

Group $2(n=16)$ : Consists of 8 males and 8 females who were given natural food sources for omegas 3,6,9 equally with the capsules content.

Group3 $(\mathrm{n}=16)$ : Consists of 8 males and 8 females who were given pharmacological supplements for omega three capsules per day.

All groups were subjected to the following pre- and post- nutrition intervention:

1-Demographic data: name, sex, height, weight.

\section{2- Nutritionalassessment:}

\section{A- Anthropometric measurements:}

The Quetelet index relates weight $(\mathrm{kg})$ to the square of the height $(\mathrm{m} 2)$, which enables calculation of body mass index (BMI) (Dwyer, 2006) It predicts disease risk in those termed underweight and in those who are obese. The World Health Organization categorizes underweight as BMI, 18.5, normal 18.5 to 24.9 , overweight 25 to 29.9 and obese 30 to 39.9, and extreme obesity40 (WHO, 1995).

\section{3-Blood sampling :}

The blood samples were immediately collected from fore arm (cubital fossa ) before and after dietary intervention from adolescent,each blood sample was divided into two portions, the first portion was taken on EDTA for blood haemoglobin estimation, while the second portion was left to clot in clean dry test tubes and then centrifuged at 3000 r.p.m for $15 \mathrm{~min}$ to separate the serum which was kept at $-20{ }^{\circ} \mathrm{c}$ for biochemical analysis.

\section{4-Biochemical investigation :}

Investigations were performed to study the changes in lipid patterns including, triglycceroles (TG), total cholesterol (TC) , HDL-c , LDL-c , VLDL-c, serum enzymes including amino trans ferases (AST, ALT) .Blood hemoglobin concentrationwas determined using commercial kit according to the method described by (Drabkin \& Austin 1932 ). Also, serum AST \& ALT activity were determined using a commercial Kit according to the method described by Reitman and Frankel (1957). For lipid profile assessment serum triglyceride was determined according to the method of Koditscheck \& Umdreit, 1969). Also, serum total cholesterol was determined according to the method of Richmond (1973). Serum LDL-cholesterol was determined according to the method of Levy (1981), while serum HDLcholesterol was determined according to the method of Burstein (1970) and serum VLDL-cholesterol was determined according to the modification of the method of Wieland and Seidel (1983). The total fatty acids were transmethylated according to the method of Stahl (1967).

\section{5- Psychological tests:}

Battery diagnostic scale assess nine variables perception, attention, memory, reading, mathematics and writing. Each variable consists of twenty questions and information is taken by the supervisors. 


\section{Supplements:}

Flax seed oil gelatin capsules (three times per day). Each capsule contains flax seed oil $1000 \mathrm{mg}$.

Alpha Linolenic Acid (omega 3) 1713 mg. Linoleic Acid (omega 6) $477 \mathrm{mg}$.

Oleic Acid (omega 9) $531 \mathrm{mg}$.

\section{Dietary intervention:}

Mahlbia with walnuts (30 gm day after day). It contains omega $3(1710 \mathrm{mg})$, Omega 6 (460 mg), Omega 9 (500 mg).

Sesame cooked as sweet (one piece $50 \mathrm{gm}$ day after day). It contains Omega 3 (1715 mg), Omega 6 (475 mg), Omega 9 (532 $\mathrm{mg})$.

Adolescent were subjected to the institutionalized nutrition before and with the intervention as follow :

Group 1 : institutionalized nutrition only.

Group 2 : institutionalized nutrition with swsame and mahlbia with nuts .

Group 3 : institutionalized nutrition with three capsules of flax seed oil / day.

All groups were submitted to this intervention for three months continuously.

\section{Statistical Analysis:}

Statistical analysis was carried out using T-test , Anova and Duncan's multiple. Continuous data were reported as mean \pm SD. Repeated-measures analysis of variance was used for intergroup comparisons of continuous data. Pairwise comparisons were performed with Bonferroni adjustment if analysis of variance was significant. In all tests, results were considered statistically significant if the $P$-value was equal or less than 0.05 . The analysis was carried out using the PROC ANOVA procedure of Statistical Analysis System ( SAS, 2006).

\section{RESULTS AND DISCUSSION}

\section{Demographic Characteristics:}

As shown in Table (1) the present study included 48 adolescents; 24 males from " Dar Elamal ", "Hadayek Al-Kobba ", Cairo, Egypt, with mean age 13.25 \pm 1.11 yrs, mean height $138 \pm 6.40 \mathrm{~cm}$ and mean weight $36.83 \pm 6.04 \mathrm{~kg}$. and 24 females from " ElShraiaa "," EL-Matriaa ", Cairo, Egypt, with mean age $13.5 \pm 1.10$ yrs, mean height $140 \pm 8.56 \mathrm{~cm}$ and mean weight $38.92 \pm 7.69 \mathrm{~kg}$.

Table (1): Demographic and Characteristics of the subjectedadolescents:

\begin{tabular}{|c|c|c|c|}
\hline \multicolumn{2}{|c|}{ Demographic data } & $\begin{array}{c}\text { Male } \\
(\mathbf{n = 2 4})\end{array}$ & $\begin{array}{c}\text { Female } \\
(\mathbf{n = 2 4})\end{array}$ \\
\hline \multirow{3}{*}{ Age $(\mathrm{yrs})$} & Range & $12: 15$ & $12: 15$ \\
\cline { 2 - 4 } & Mean \pm SD & $\mathbf{1 3 . 2 5} \pm 1.11$ & $\mathbf{1 3 . 5} \pm 1.10$ \\
\hline \multirow{2}{*}{ Height $(\mathrm{Cm})$} & Range & $130: 150$ & $120: 155$ \\
\cline { 2 - 4 } Weight $(\mathrm{Kg})$ & Mean $\pm S D$ & $\mathbf{1 3 8} \pm 6.40$ & $\mathbf{1 4 0} \pm 8.56$ \\
\hline \multirow{2}{*}{} & Range & $30: 45$ & $31: 52$ \\
\cline { 2 - 4 } & Mean $\pm S D$ & $\mathbf{3 6 . 8 3} \pm 6.04$ & $\mathbf{3 8 . 9 2} \pm 7.69$ \\
\hline
\end{tabular}

*SD: Standard Division.

\section{2- Nutritional assessment:}

The nutritional status of the sample was assessed by measuring the height, weight, and body mass index, as well as the food intake of nutrients by 24 hours recall for three days and calculating the average on this basis. Laboratory analysis of the blood sample was performed to confirm the nutritional status assessment; Hemoglobin (Hb.), HDL-c, LDL-c, VLDL-c, TG, TC, ALT, AST.

\section{2-a. Anthropometric measurements:}

As illustrated in Table (2), the mean heights for male and female weres $138 \pm 6.40 \mathrm{~cm}$ and $140 \pm 8.56 \mathrm{~cm}$ comparing 
Effect of Omega's different sources supplementation on some biological assessments and mental efficiency at adolescence

with calculated normal heights $140 \pm 7.5$ $\mathrm{cm}$ and $135 \pm 15.3 \mathrm{~cm}$, respectively. The mean weights for adolescent male and female were $36.83 \pm 6.04 \mathrm{~kg}$ and $38.92 \pm 7.69 \mathrm{~kg}$ comparing with calculated normal weights $35.8 \pm 6 \mathrm{~kg}$ and $37.25 \pm 5.20$ $\mathrm{kg}$ respectively. Also, the mean values of BMI for male and female were $23.45 \pm 1.02,23.75 \pm 1.43$, respectively.

Table (2). Anthropometric measurements of the subjected adolescents.

\begin{tabular}{|c|l|c|c|}
\hline \multicolumn{2}{|l|}{ Anthropometric measurements } & Male $(\mathbf{n}=\mathbf{2 4})$ & Female $(\mathbf{n}=\mathbf{2 4})$ \\
\hline \multirow{3}{*}{ Height $(\mathrm{Cm})$} & Mean \pm SD & $\mathbf{1 3 8} \pm 6.40$ & $\mathbf{1 4 0} \pm 8.56$ \\
\cline { 2 - 4 } & Normal & $140 \pm 7.5$ & $135 \pm 15.3$ \\
\hline \multirow{2}{*}{ Weight $(\mathrm{Kg})$} & Mean \pm SD & $\mathbf{3 6 . 8 3} \pm 6.04$ & $\mathbf{3 8 . 9 2} \pm 7.69$ \\
\cline { 2 - 4 } & Normal & $35.8 \pm 6$ & $37.25 \pm 5.20$ \\
\hline BMI & Mean \pm SD & $\mathbf{2 3 . 4 5} \pm 1.02$ & $\mathbf{2 3 . 7 5} \pm 1.43$ \\
\hline
\end{tabular}

SD: Standard Division.

The index of body mass:

Under weight : $(<18.5)$, Over weight: $(25$ - 29.9), Extreme obesity $(<40)$

Normal :(18.5 - 24.9), Obese:(30 - 39.9).

There was a statistically significant difference between pre- andpostintervention for $\mathrm{Hb}$., ALT, AST at $\mathrm{p}<$ 0.01 in nutritional and medical groups. These improvements were attributed to the dietary intervention with omega's different sources. As showed in Table (3) the mean values of $\mathrm{Hb}$ were $12.04,12.03 \mathrm{~g} / \mathrm{dl}$ for control group pre-post intervention, respectively, while in nutritional group were $12.7,14.5 \mathrm{~g} / \mathrm{dl}$ pre-post, respectively, and in medical group were 12.3, $14.2 \mathrm{~g} / \mathrm{dl}$ pre- post, respectively.

Table (3). Effect of omega's different sources supplementation on Hb, AST, ALT for subjected adolescents (Mean \pm SD).

\begin{tabular}{|c|c|c|c|c|}
\hline \multicolumn{2}{|c|}{} & $\begin{array}{c}\text { Pre- } \\
\text { intervention }\end{array}$ & $\begin{array}{c}\text { Post- } \\
\text { intervention }\end{array}$ & sig. \\
\hline \multirow{3}{*}{ Hb $(\mathrm{g} / \mathrm{dl})$} & Control & $12.04 \pm 0.82$ & $12.03^{\mathrm{b}} \pm 0.8$ & - \\
\cline { 2 - 5 } & Nutritional & $12.7 \pm 0.8$ & $14.5^{\mathrm{a}} \pm 0.8$ & .01 \\
\cline { 2 - 5 } & Medical & $12.3 \pm 0.8$ & $14.2^{\mathrm{a}} \pm 1.1$ & .01 \\
\hline \multirow{3}{*}{ ALT $(\mathrm{u} / \mathrm{l})$} & Control & $12.81 \pm 1.64$ & $12.9^{\mathrm{b}} \pm 1.7$ & - \\
\cline { 2 - 5 } & Nutritional & $9.1 \pm 2.7$ & $7.7^{\mathrm{a}} \pm 1.5$ & .01 \\
\cline { 2 - 5 } & Medical & $12.3 \pm 0.8$ & $14.2^{\mathrm{a}} \pm 1.1$ & .01 \\
\hline \multirow{3}{*}{ AST $(\mathrm{u} / \mathrm{l})$} & Control & $16 \pm 4.17$ & $15^{\mathrm{b}} \pm 3.9$ & - \\
\cline { 2 - 5 } & Nutritional & $22.6 \pm 5.2$ & $16^{\mathrm{b}} \pm 4.1$ & .01 \\
\cline { 2 - 5 } & Medical & $24.5 \pm 5.7$ & $18.1^{\mathrm{a}} \pm 3.3$ & .01 \\
\hline
\end{tabular}

Control group, which didn't receive any thing.

Nutritional group, which given natural food sources of omegas 3,6,9.

Medical group, which given pharmacological supplements of omegas (three capsules/ day).

a , b , c: Means with different letters among intervention in the same column are Significantly different . 
This result disagreed with Afshin et al. (2008) who reported that 45 subjects (25 in the omega-3 and 20 in the placebo group completed the study). No significant changes were observed in blood hemoglobin, serum iron, and required dose of intravenous iron in either within or between group comparisons. Additionally, erythropoietin resistance index as well as required dose of intravenous erythropoietin showed no significant change in the omega-3 group compared to the placebo group. Although a relative alleviation in inflammatory state appeared in the omega-3 group, the mean differences of inflammatory and antiinflammatory markers between the two groups did not reach statistically significant level except for ratio and serum ferritin level which showed significant changes in favor of omega-3 treatment ( $\mathrm{P}$ $<0.001$ and $\mathrm{P}=0.003$, respectively).

While agreed with Varnalidis et al . ( 2011) who observed that animals fed an omega 3 rich diet exhibited a statistically significant increase in hematocrit and hemoglobin levels, compared to animals drinking tap water, and a trend towards histopathological and clinical improvement, with the administration of omega 3 fatty acids ameliorating epithelial erosion by day 8 post-DSS, but no statistically significant difference was observed between group A and group B animals at 4 or 8 days post-DSS. Also, a statistically significant increase in neutrophil infiltration was observed, as depicted by myelohyperoxidase activity.

Regarding ALT , AST, the mean values of ALT were 12.81, $12.9 \mathrm{u} / \mathrm{l}$ for control group pre - post, respectively, 9.1, $7.7 \mathrm{u} / 1$ in pre and post intervention nutritional group, $12.3,14.2 \mathrm{u} / \mathrm{l}$ in pre and post intervention medical group. The mean values of AST were 16, $15 \mathrm{u} / \mathrm{l}$ for control group pre and post intervention, respectively, while in nutritional group these were 22.6,16 u/l for pre - post intervention, respectively, and in medical group these were $24.5,18.1 \mathrm{u} / 1$ for pre and post intervention, respectively. It could be noticed from the tabled means that nutritional and medical groups were improved by the intervention, specially nutritional, which was more effective in AST and ALT improving.

This result disagreed with Wenxia et al. (2016) who reported that it was not significant on ALT, AST, when used omega supplementation in treatment.

There were a statistically significant difference between pre and post intervention for $\mathrm{TG}, \mathrm{TC}$ at $\mathrm{p}<0.01$ in nutritional and medical groups (Table 4). These improvements were attributed for the dietary intervention with omega's different sources.

Table (4). Effect of omega's different sources supplementation on serum lipids for subjected adolescents (Mean \pm SD).

\begin{tabular}{|c|c|c|c|c|}
\hline \multirow{2}{*}{ TG(mg/dl) } & Pre-intervention & Post-intervention & Sig. \\
& Control & $79 \pm 16$ & $77^{\mathrm{a}} \pm 15.3$ & \\
\cline { 2 - 5 } & Nutritional & $88.8 \pm 13.7$ & $68.1^{\mathrm{a}} \pm 9.1$ & .01 \\
\cline { 2 - 5 } & Medical & $78 \pm 10.7$ & $60^{\mathrm{b}} \pm 9.1$ & .01 \\
\hline \multirow{2}{*}{ TC(mg/dl) } & Control & $147 \pm 87$ & $148^{\mathrm{a}} \pm 88.1$ & .01 \\
\cline { 2 - 5 } & Nutritional & $159.2 \pm 18.2$ & $138.4^{\mathrm{b}} \pm 19.2$ & .01 \\
\cline { 2 - 5 } & Medical & $170.5 \pm 18.2$ & $153.9^{\mathrm{a}} \pm 19.2$ & \\
\hline
\end{tabular}

Control group, which didn't receive any thing.

Nutritional group, which given natural food sources for omega 3,6,9.

Medical group, which given pharmacological supplements for omega three capsule/day.

a , b , c: Means with different letters among intervention in the same column are significantly different. 

and mental efficiency at adolescence

Table (4) exhibited the mean values of TG were $79,77 \mathrm{~m} \mathrm{~g} / \mathrm{dl}$ for control group pre - post respectively, while in nutritional group were 88.8, 68.1 $\mathrm{mg} / \mathrm{dl}$ pre - post respectively, and in medical group were $78,60 \mathrm{mg} / \mathrm{dl}$ pre post, respectively. And the mean values of TC were $147,148 \mathrm{mg} / \mathrm{dl}$ for control group pre - post, respectively, while in nutritional group were $159.2,138.4 \mathrm{mg} / \mathrm{dl}$ pre - post respectively, and in medical group were $170.5,153.9 \mathrm{mg} / \mathrm{dl}$ pre - post .From this result it was found an improved in TG in intervention groups control group specially medical group, while it noticed an improved in TC in intervention groups than control group especially nutritional group .

This result agreed with Vasil'ev et al. (2009) who reported that therapy with omega-3 PUFAs resulted in a significant decrease of serum triglycerides from 3.04 +/- 0.39 to $1.91+/-0.15 \mathrm{mmol} / \mathrm{l}(-37.2 \%)$. Its combination with hypotensive therapy reduced mean AP from $114.5+/-2.4$ to $106.3+/-1.8 \mathrm{~mm} \mathrm{Hg}(\mathrm{p}<0.01)$. Also, omega-3 PUFAs increased amplitude fluctuations in LDF-grams in endothelial and neurogenic ranges by 33.3 and $30.8 \%$ respectively, tissue hemoperfusion rate

There was a statistically significant difference between pre and post intervention for LDL-c, HDL-c , VLDL-c at $\mathrm{p}<0.01$ in nutritional and medical groups. These improvements were attributed for the dietary intervention with omega's different sources. Table (5) illustrated that the mean values of HDL-c were 37.2 , $38 \mathrm{mg} / \mathrm{dl}$ for control group pre - post respectively , while in nutritional group were 42.3 , $53.4 \mathrm{mg} / \mathrm{dl}$ pre - post, respectively, and in medical group were $39.3,50.3 \mathrm{mg} / \mathrm{dl}$ pre - post from $4.9+/-0.13$ to $5.3+/-0.15 \mathrm{U}$ (p < $0.05)$, capillary blood flow reserve by $13.7 \%(\mathrm{p}<0.05)$, maximum tissue hemoperfusion by $18.8 \%(\mathrm{p}<0.01)$, and coefficient of variation of tissue blood flow by $26.9 \%$. Blood C-reactive protein level dropped by $40.7 \%$. These changes were absent in control patients. It is concluded that correction of omega-3 PUFAs deficiency in patients with HA and MS reduces hyperlipidemia, has moderate antihypertensive effect, improves endothelial function and microcirculation. Multifunctional action of omega-3 PUFAs gives reason to recommend them for the treatment of MS. At the same direction, Caniato. et al. (2006) confirmed that Participants taking omega-3 fatty acids demonstrated a statistically significant reduction in mean serum triglyceride levels of $22 \%$. There was an associated increase in total cholesterol $(6.6 \%)$ and low-density lipoprotein cholesterol (22\%).

Also, agreed with Ateya et al. (2017) who reported that children in omega-3 group showed a highly significant reduction in total cholesterol and a highly significant increase in glutathione peroxidase and superoxide dismutase levels.

respectively, it could be noticed more improvement in nutritional group than medical and control groups. And the mean values of LDL-c were 95.4, $90 \mathrm{mg} / \mathrm{dl}$ for control group pre - post respectively , while in nutritional group were 99.1, $71.3 \mathrm{mg} / \mathrm{dl}$ pre - post respectively, and in medical group were 115.6, $91.6 \mathrm{mg} / \mathrm{dl}$ pre - post , from this result it was found an improvement in nutritional group than medical and control groups. The mean values of VLDL-c were $15.8,15.4 \mathrm{mg} / \mathrm{dl}$ for control group 
Sohila A.F. Hassan et al.

pre - post respectively, while in nutritional group were 17.7, 13.6 $\mathrm{mg} / \mathrm{dl}$ pre - post respectively, and in medical group were $15.5,12 \mathrm{mg} / \mathrm{dl}$ pre - post respectively, it could be noticed an improved in intervention groups than control group especially medical group. This result agreed with Tianhua et al. (2016) who indicated that omega-3 fatty acids ( O3FA ) supplementation reduced TG by 0.61 , LDL by 0.35 . However, O3FA had no significant effect on TC, HDL, albumin, hemoglobin, homocysteine, glucose, lipoprotein (a), and ferritin. O3FA supplementation is associated with lower several serum lipids and vascular inflammation markers in patients with endstage renal disease (ESRD). Also agreed with Wenxia Luet al ( 2016 ) who demonstrated that omega-3 PUFAs improved liver fat, GGT, TG, and HDL in patients with nonalcoholic fatty liver disease (NAFLD). Therefore, n-3 PUFAs may be a new treatment option for NAFLD.

Table (5). Effect of omega's different sources supplementation on cholesterol fractions for subjected adolescents (Mean \pm SD).

\begin{tabular}{|c|c|cc|c|}
\hline \multicolumn{2}{|c|}{} & $\begin{array}{c}\text { Pre- } \\
\text { intervention }\end{array}$ & $\begin{array}{c}\text { Post- } \\
\text { intervention }\end{array}$ & Sig. \\
\hline \multirow{3}{*}{ HDL-c (mg/dl ) } & Control & $37.2 \pm 4.1$ & $38^{\mathrm{b}} \pm 4.2$ & \\
\cline { 2 - 5 } & Nutritional & $42.3 \pm 5.2$ & $53.4^{\mathrm{a}} \pm 7.1$ & .01 \\
\cline { 2 - 5 } & Medical & $39.3 \pm 5.2$ & $50.3^{\mathrm{a}} \pm 7.1$ & .01 \\
\hline \multirow{3}{*}{ LDL-C (mg/dl ) } & Control & $95.4 \pm 12.3$ & $90^{\mathrm{a}} \pm 11.2$ & .01 \\
\cline { 2 - 5 } & Nutritional & $99.1 \pm 13.7$ & $71.3^{\mathrm{b}} \pm 10.3$ & .01 \\
\cline { 2 - 5 } & Medical & $115.6 \pm 12.7$ & $91.6^{\mathrm{a}} \pm 12.3$ & .01 \\
\hline \multirow{3}{*}{ VLDL-C(mg/dl) } & Control & $15.8 \pm 2.1$ & $15.4 \pm 1.9$ & .01 \\
\cline { 2 - 5 } & Nutritional & $17.7 \pm 2.7$ & $13.6 \pm 3.1$ & $12 \pm 3.1$ \\
\cline { 2 - 5 } & Medical & $15.5 \pm 3.7$ & & \\
\hline
\end{tabular}

Control group, which didn't receive any thing.

Nutritional group, which given natural food sources for omega 3,6,9.

Medical group, which given pharmacological supplements for omega three capsules per day. $\mathrm{a}, \mathrm{b}, \mathrm{c}$ : Means with different letters among intervention in the same column are significantly different.

As seen in Table (6)the mean values of perception were 47.7, 40.4 for control group pre - post respectively, while in nutritional group were 47.8, 20.9 pre post respectively, and in medical group were $51.1,21.1$ pre - post respectively, it was noticed that there was an improvement in intervention groups than control group especially nutritional group.

This result were agreed with Richardson and Montgomery (2005) who reported on 117 children ages 5 to 12 years old with developmental coordination disorders and associated behavior and/or learning difficulties, who were treated for 3 months with an omega-3 fatty acid, omega-6 supplement, or an olive oil placebo in a randomized, controlled double-blind trial. Results of this study indicated significant benefits for active treatment over the placebo for both reading and spelling progress. 

and mental efficiency at adolescence

Table (6). The effect of omega's different sources supplementation on perception for subjected adolescents (Mean \pm SD).

\begin{tabular}{|l|c|c|c|c|}
\hline \multicolumn{2}{|c|}{} & $\begin{array}{c}\text { Pre- } \\
\text { intervention }\end{array}$ & $\begin{array}{c}\text { Post- } \\
\text { intervention }\end{array}$ & Sig. \\
\hline \multirow{3}{*}{ Perception $(0 \rightarrow 61)$} & Control & $47.7 \pm 6.3$ & $40.4^{\mathrm{a}} \pm 5.4$ & \\
\cline { 2 - 5 } & Nutritional & $47.8 \pm 4.2$ & $20.9^{\mathrm{b}} \pm 3.9$ & .01 \\
\cline { 2 - 5 } & Medical & $51.1 \pm 5.9$ & $21.1^{\mathrm{b}} \pm 5.3$ & .01 \\
\hline
\end{tabular}

Control group, which didn't receive any thing.

Nutritional group, which given natural food sources for omega 3,6,9.

Medical group, which given pharmacological supplements for omega three capsules per day.

Normal dispersion: $(0-20) *$ Light dispersion: $(21-40)$.

Medium dispersion: ( $41-60$ ).*High dispersion: ( > 61 ).

$\mathrm{a}, \mathrm{b}, \mathrm{c}$ : Means with different letter among intervention in the same column are significantly different.

Table (7) showed the mean values of remember were 51.3, 45 for control group pre - post respectively, while in nutritional group were 49.7, 20.2 pre - post respectively, and in medical group were 49.4, 21.5 pre - post , respectively. , it was noticed that there was an improvement in intervention groups than control group especially nutritional group.

This were agreed with Isabelle et al. (2011) who found that 30 days EPArich supplementation decrease functional activation relative to cognitive performance (Colour / Word Stroop, Spatial Working Memory), whereas the DHA-rich supplementation had a lesser effect compared with EPA-rich supplementation. Also, this agreed with Yurko-Mauro et al. (2010) who reported that intention-to-treat analysis demonstrated significantly fewer PAL six pattern errors with DHA versus placebo at 24 weeks (difference score, -1.63 \pm 0.76 $[-3.1,-0.14,95 \% \mathrm{CI}], \mathrm{P}=0.03)$.

DHA supplementation was also associated with improved immediate and delayed Verbal Recognition Memory scores $(\mathrm{P}<.02)$, but not working memory or executive function tests. Plasma DHA levels doubled and correlated with improved PAL scores $(\mathrm{P}<0$.02) in the DHA group. DHA was well tolerated with no reported treatment-related serious adverse events.

Table (7). Effect of omega's different sources supplementation on remember for subjected adolescents (Mean \pm SD).

\begin{tabular}{|c|c|c|c|c|}
\hline \multicolumn{2}{|c|}{} & Pre-intervention & Post-intervention & Sig. \\
\hline \multirow{2}{*}{$\begin{array}{c}\text { Remember } \\
(0->61)\end{array}$} & Control & $51.3 \pm 5.4$ & $45^{\mathrm{a}} \pm 5.1$ & \\
\cline { 2 - 5 } & Nutritional & $49.7 \pm 4.8$ & $20.2^{\mathrm{b}} \pm 5.4$ & .01 \\
\cline { 2 - 5 } & Medical & $49.4 \pm 4.5$ & $21.5^{\mathrm{b}} \pm 3.4$ & .01 \\
\hline
\end{tabular}

Control group, which didn't receive any thing.

Nutritional group, which given natural food sources for omega 3,6,9.

Medical group, which given pharmacological supplements for omega three capsules per day.

Normal dispersion: ( 0 - 20 )*Light dispersion: $(21-40)$.

Medium dispersion: ( $41-60$ ).*High dispersion: ( $>61$ ).

$\mathrm{a}, \mathrm{b}, \mathrm{c}$ : Means with different letter among intervention in the same column are significantly different.

As seen in Table (8) the mean values of attention were 52.1, 50.1 for control group pre - post, respectively, while in nutritional group these were 49.3, 
Sohila A.F. Hassan et al.

19.6 pre - post, respectively , and in medical group these were $51.5,15.8$ pre post respectively. It was noticed that there was an improvement in intervention groups than control group especially medical group. This result were agreed with Mcnamara et al.( 2010) who revealed that 8 weeks DHA supplementation led to an increase in functional activation in the dorsolateral prefrontal brain regions during a sustained visual attention task (a simple continuous performance task) compared with presupplementation in healthy children aged 8 to 10 years. Also, results agreed with Bauer et al. (2011) who showed that 30 days EPA-rich supplementation improved performance on a choice reaction time task in young adults and enhanced neural recovery for high-contrast multifocal visual evoked potentials (mfVEPs). In addition, Milte et al. (2011) reported that omega-3 polyunsaturated fatty acid levels may contribute to improve attention deficit (AD) and related developmental problems with and without learning difficulties.

Portwood (2006) demonstrated improvement inattention and hyperactivity through supplementation of omega-3 fatty acids. He found that 3 months of supplementation with omega-3 fatty acids improved inattentiveness scores for teenagers, from an average of 94 at the beginning of the study to 17 at the end of 3 months.

Table (8). Effect of omega's different sources supplementation on attention for subjected adolescents (Mean \pm SD).

\begin{tabular}{|c|c|c|c|c|}
\hline \multicolumn{2}{|c|}{} & Pre-intervention & Post-interentiont & Sig. \\
\hline \multirow{3}{*}{$\begin{array}{c}\text { Attention } \\
(0 \rightarrow->1)\end{array}$} & Control & $52.1 \pm 5.4$ & $50.1^{\mathrm{a}} \pm 5.2$ & \\
\cline { 2 - 5 } & Nutritional & $49.3 \pm 4.6$ & $19.6^{\mathrm{b}} \pm 1.9$ & .01 \\
\cline { 2 - 5 } & Medical & $51.5 \pm 5.4$ & $15.8^{\mathrm{b}} \pm 1.7$ & .01 \\
\hline
\end{tabular}

Control group, which didn't receive any thing.

Nutritional group, which given natural food sources for omega 3,6,9.

Medical group, which given pharmacological supplements for omega three capsules per day.

Normal dispersion: ( 0 - 20 )*Light dispersion: $(21-40)$.

Medium dispersion: ( $41-60$ ).*High dispersion: (> 61 ).

$\mathrm{a}, \mathrm{b}, \mathrm{c}$ : Means with different letter among intervention in the same colum are significantly different .

\section{Conclusion}

Omega polyunsaturated fatty acids are important through out life.The support of different omega sources led to improving nutritional status. This was reflected in an increase in hemoglobin, beneficial fats (HDL-C) and a decrease in LDL-C , VLDL-C, TG, TC, AST, ALT. Also, improve mental efficiency, which was reflected in improved perception, remembering and attention. Therefore, the results of this research tend to use omega as fat to improve memory, perception, attention and mental efficiency in general.

\section{REFERENCES}

Afshin, G.; Mohammad-Reza, K.; Simin, D.K.; Effat, R.; Alireza, A.; SeyedSaeed, H.N. and Mohammad, A.M. (2008). Potential effects of omega-3 fatty acids on anemia and inflammatory markers in maintenance hemodialysis patients. Daru, 22(1):11. doi:10.1186/2231.22-11.

Antalis, C.J.; Stevens, L.J.; Campbell, M.; Pazdro, R.; Ericson, K. and Burgess, J.R. (2006). Omega-3 fatty acid status inattention - deficit / hyperactivity disorder. Prostaglandins Leukotessent Fatty Acids, 75:299-308. 


\section{Effect of Omega's different sources supplementation on some biological assessments and mental efficiency at adolescence}

Ateya, A.M.; Sabri, N.A.; El Hakim, I. and Shaheen, S.M.. (2017). Effect of Omega-3 fatty acids on serum lipid profile and oxidative stress in pediatric patients on regular hemodialysis: a randomized placebo-controlled study. J. Ren. Nutr., 3:169-174.

Burstein, M (1970). HDL-cholesterol determination after separation of high density lipoprotein lipid. J. Lip. Res., 11:583.

Caniato, R.N.; Alvarenga, M.E. and Garcia-Alcaraz, M.A. (2006). Effect of omega-3 fatty acids on the lipid profile of patients taking clozapine. Aust. Nzj Psychiatry, 40(8): 691-7.

Covington, M.B. (2004).Omega 3 fatty acids. Am. Fam. Physician,70(1): 133-140 .

Drabkin, A and Austin, M. (1932). Spectrophotometric constants for common hemoglobin. Derivitives in human, dog and rabbit blood. J. Biol. Chem., 98:719-733.

Dwyer, J. (2006). Harrisons Principles of Internal Medicine; Nutritional Requirements and Dietary Assessment. USA: The McGrawHill Companies.

Gadoth, N. (2008). On fish oil and omega3 supplementation in children: the role of such supplementation on attention and cognitive dysfunction. Brain Dev., 30(5):309-12.

Germano, M.; Meleleo, D.; Montorfano, G.; Adorni, L.; Negroni, M.; Berra, B. and Rizzo, A.M. (2007). Plasma, red blood cells phospholipids and clinical evaluation after long chain omega3 supplementation in children with attention deficit hyperactivity disorder (ADHD). Nutr. Neurosci., 10:1-9.

Isabelle, B.; David, P.C.; Andrew, P.; Renee, R.; Robyn, C. and Sheila,
G.C. (2011). Omega-3 fatty acids modify human cortical visual processing-a double-blind, crossover study. doi.org 10.1371/journal.pone0028214 .

Koditscheck, L.K. and umbreit,W.W. (1969). Triglycerides. Gpo-PAP Method J. Bacteriol, 98: 10631068.

Levy, R.T. (1981). Cholesterol; lipoprotein, apoploteins and heart diseases present status and future prospects. Clin. Chem., 27:653.

Lunn,J. (2006). The health effects of dietary unsaturated fatty acids. Nutr. Bull. doi.org/10.1111/j.14673010: 52-54 .

Mazza. M.; Pomponi, M.; Janiri, L.; Bria,

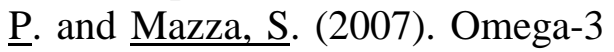
fatty acids and antioxidants in neurological and psychiatric diseases: an overview. Prog. Neuropsychopharmacol. Biol. Psychiatry, 30,31(1):12-26.

McNamara, R.K. and Carlson, S.E. (2006). Role of Omega-3 fatty acids in brain development and function: Potential implications for the pathogenesis and prevention of Psychopathology. Prostaglandins Leukot Essent. Fatty Acids, 75:329-349.

McNamara, R.K.1.; Jandacek, R.; Rider, T.; Tso, P.; Cole-Strauss, A.and Lipton, J.W. (2010). Omega3 fatty acid deficiency increases constitutive pro-inflammatory cytokine production in rats: relationship with central serotonin turnover. Prostaglandins leukot Essent. Fatty Acids, 83(4-6) :185189/doi10.1016/j-plefa.

Milte, C.M.; Sinn, N.; Buckley, J.D.; Coates, A.M.; Young, R.M. and Howe, P.R. (2011). Polyunsaturated fatty acids, cognition and literacy in children with ADHD with and without 
Sohila A.F. Hassan et al.

learning difficulties. J. Child Health Care, 15:299-311.

Mitruka, B.M.; Rawnsly, H.M. and Vadehra, B.V. (1977). Clinical biochemical and hematological reference values in normal experimental animals. Masson publishing USA. Inc. New York, Paris. Barcelona, Million, Pp.4157.

Portwood, M. (2006). The role of dietary fatty acids in children's behavior and learning. Nutr. and Health, 18(3): 219-232.

Reitman, S. and Frankel, S. (1957). A colorimetric method for the determination of serum glutamic oxalacetic and glutamic pyruvic transaminases.

AM.J. Clin.Path.,28:56-63 .

Richardson, A.J. and Montgomery, P. (2005).The Oxford-Durham Study: A randomized, controlled trial of dietary supplementation with Fatty Acids in Children with Developmental Coordination Disorder. Pediatrics, 115 (5):13601366.

Richmond, W.(1973). Preparation and properties of a cholesterol oxidase from nocardial SP. and its application to the enzyme assay of total cholesterol. Sprum Clin. Chem.,19:1350-1356.

SAS program (2006). SAS/STAT User's Guide Release 6.12 addition. Cary, NC, USA : SAS Inst. Inc.

Sorgi, P.J.; Hallowell, E.M.; Hutchins, H.L. and Sears, B. (2007). Effects of an openlabel pilot study with high-dose EPA/DHA concentrates on plasma phospholipids and behavior in children with attention deficit hyperactivity disorder. Nutr. J., 6:16.
Stahl, E. (1967). Thin layer chromatography a laboratory handbook, Springer verlag, Berlin, Heidelberg, New York, page 359.

Tianhua, X.; Yiting, S.; Wei, S.; Li, Y., Li, S.; Linlin, $\quad$ L.; Jianfei, $\quad M$. and Lining, W. ( 2016 ). Effect of omega-3 fatty acid supplementation on serum lipids and vascular inflammation in patients with end-stage renal disease: a meta-analysis. Scientific Reports 6, doi:10.10381 srep 39346.

Varnalidis, I.; Ioannidis, O.; Karamanavi, E.; Ampas, Z.; Poutahidis, T.; Taitzoglou, I.; Paraskevas, G. and Botsios, D. (2011). Omega 3 fatty acids supplementation has an ameliorative effect in experimental ulcerative colitis despite increased colonic neutrophil infiltration. Rev. Esp. Enferm. Dig.,103(10):511-8.

Wenxia, L.; Sainan, L.; Jingjing, L.; Jianrong, W.; Rong, Z.; Yuqing, Z.; Qin, Y.; Yuanyuan, Z.; Fan, W.; Yujing, X.; Kan, C.; Tong, L.; Jie, L.; Yingqun, Z. and Chuanyong, G. (2016). Effects of omega-3 fatty acid in nonalcoholic fatty liver disease: A Meta-Analysis. Gastroenterol. Respract :1459790,doi:10.1155.

Wieland, K.L. and Seidel, D. (1983). LDL-cholesterol: fully enzymatic colorimetric test J. Lipid Res., 24:904.

Yurko-Mauro, K.L.; McCarthy, D.; Rom, D.; Nelson, E.B.; Ryan, A.S.; Blackwell, A.; Salem, N. Jr.; Stedman, $\quad$ M.; MIDAS Investigators (2010). Beneficial effects of docosahexaenoic acid on cognition in age-related cognitive decline. Alzheimers Dement (6):456-64. doi10.1016/j/jalz. 
Effect of Omega's different sources supplementation on some biological assessments and mental efficiency at adolescence

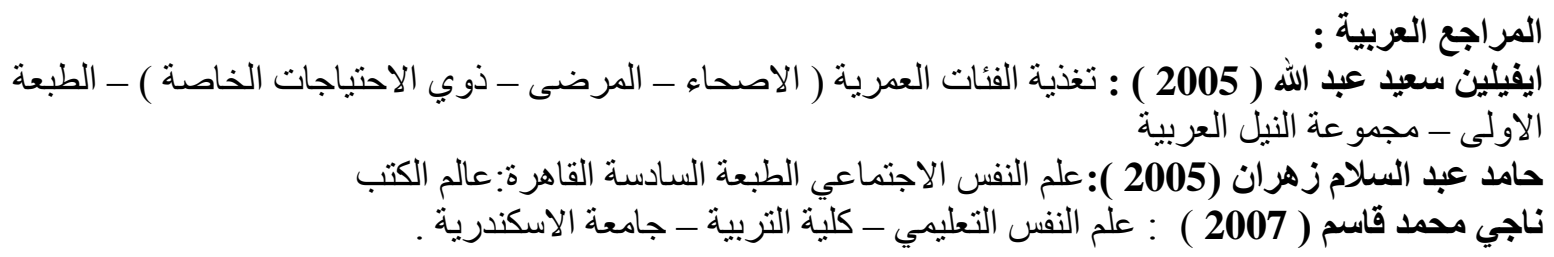

تأثير الدعم بمصادر مختلفة للاوميجا على بعض القياسات الحيوية والكفاءةالذهنية بمرحلة المراهقة

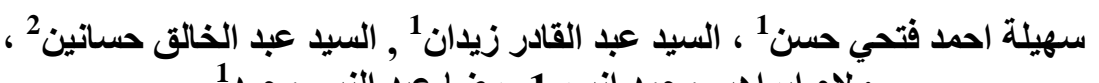

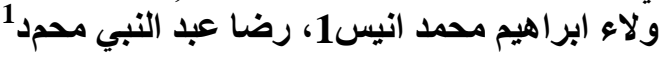

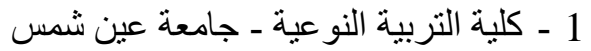

2 - قسم الكيمياء الحيوية وكيمياء التغذية ـ المعهد القومي للتغذية ـ وزارة الصحة و السكان ـ القاهرة

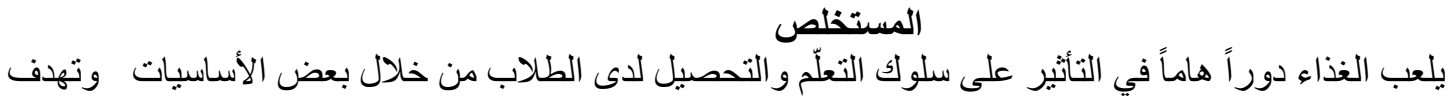

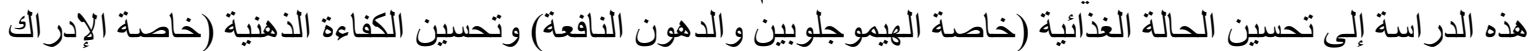

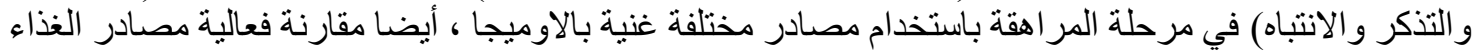

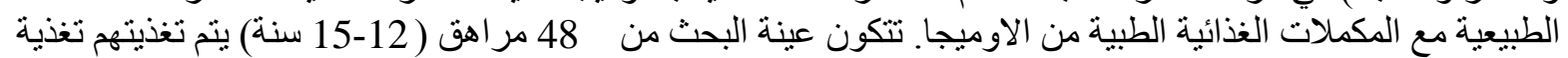

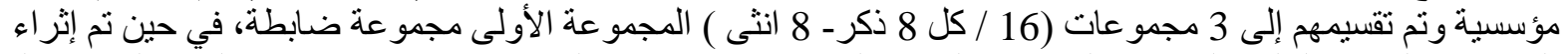

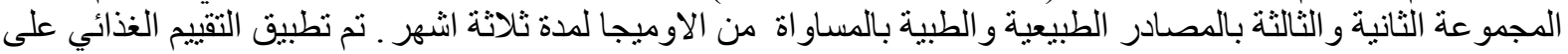

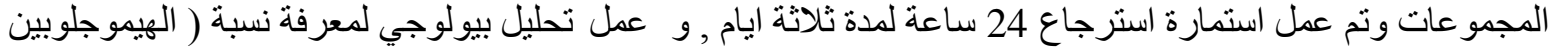

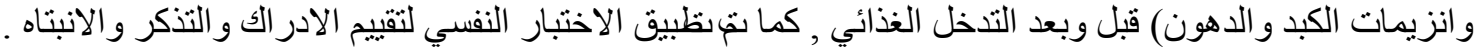

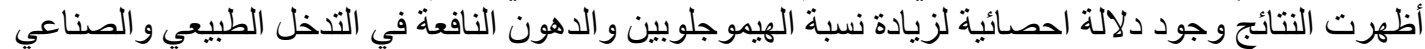

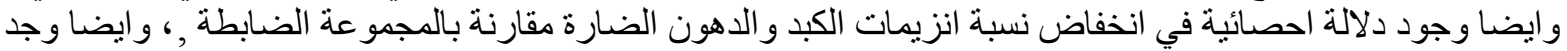

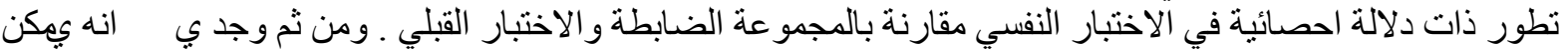

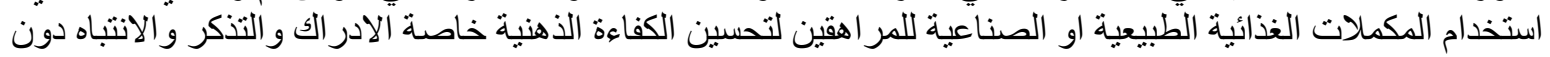
التمبز للمصدر . 